J Forensic Investigation

August 2014 Vol.:2, Issue:3

(C) All rights are reserved by Li et al.

\title{
Genetic Markers for Sex Identification in Forensic DNA Analysis
}

\begin{abstract}
Keywords: Amelogenin; AMEL; SRY; TSPY; DXYS156; STS
Abstract

The ability to determine the sex of an individual based on DNA evidence can be crucial in instances such as identification of victims of mass disaster, missing persons investigations, and sexual assault cases. The $Y$ chromosome marker amelogenin is currently in widespread use for detemination of chromosomal sex of an unknown DNA donor and differentiating the relative contributions of male and female DNA in a mixed forensic sample. However, many cases of the failure of the amelogenin marker to correctly determine the sex of DNA donors have been reported, causing the usefulness of the amelogenin marker in forensics to be questioned. In this paper we review use of amelogenin as a marker for sex identification in forensics and describe four additionalY chromosome markers, sex-detemining region Y (SRY), Y-encoded testis-specific protein (TSPY), locus DXYS156, and steroid sulfatase (STS). The SRY, TSPY, DXYS156, and STS markers each have properties that could be used for developing more rigorous methods of testing forensic DNA samples for a $Y$ chromosome or the presence of specific reproductive or secondary sex characteristics.
\end{abstract}

\section{Introduction}

In forensic casework there is often a need to determine the sex of an individual based on DNA evidence in instances such as identification of victims of mass disaster, missing persons investigations, and sexual assault cases. Analysis of Y-specific target sequences on the $\mathrm{Y}$ chromosome is a largely effective method for determining the chromosomal sex of an individual and estimating the ratio of male and female DNA in a mixed forensic sample.

The sex typing marker amelogenin is incorporated in most commercially available multiplex short tandem repeat (STR) kits and is currently the most common sex typing marker used in forensic casework. For a DNA profile to be accepted into the US National DNA Index System (NDIS), which is the national level of the Combined DNA Index System (CODIS), inclusion of the amelogenin marker is required for relatives of missing persons, along with the 13 CODIS Core Loci [1]. The amelogenin test must be attempted for DNA profiles of missing persons and unidentified human remains, and is accepted but not required for offender and forensic profiles [1]. In addition to amelogenin, alternative $\mathrm{Y}$-specific markers are being explored, which, when used in place of or in conjunction with the standard amelogenin test may provide more consistently reliable sex typing information for forensic casework.

It is worth noting that while the ultimate goal of sex typing in forensic investigations is often to discover the legal or perceived gender of an individual, there will always exist cases in which an individual's chromosomal sex, as discovered by DNA sex typing, does not match legal gender or gender presentation [2]. However, because legal gender and chromosomal sex do correspond in the majority of cases, methods for accurate determination of chromosomal sex do and will continue to have widespread use in forensic investigations.

\section{Journal of}

Forensic Investigation

\section{Erin Butler and Richard $\mathrm{Li}^{*}$}

Forensic Science Program, Department of Sciences, John Jay College of Criminal Justice, The City University of New York, New York, NY 10019, USA

Address for Correspondence

Dr. Richard Li, Ph.D., Forensic Science Program, Department of Sciences, John Jay College of Criminal Justice, The City University of New York, New York, NY 10019, USA, Tel : 646557 4886; E-mail : rli@jjay.cuny.edu

Submission: 29 July, 2014

Accepted: 18 August, 2014

Published: 21 August, 2014

\section{Forensic Markers For Sex Identification}

\section{Amelogenin}

The application of amelogenin marker in forensic caseworks: The amelogenin (AMEL) locus encodes a matrix protein forming tooth enamel. Mutations in the AMEL locus can lead to the enamel defect known as amelogenesis imperfecta, which results in the abnormal formation of tooth enamel [3]. The AMEL locus has two homologous genes: AMELX, which is located on the distal short arm of the $\mathrm{X}$ chromosome in the p22.1-p22.3 region (Figure 1; Table 1), and AMELY, located near the centromere of the Y chromosome at p11.2 [4-6] (Figure 1; Table 1).

Nakahori et al. found distinct sequences for AMELX and AMELY with $89 \%$ homology between the two [4]. Salido et al. identified 7 exons for AMELX and AMELY (Figure 2) and found that human amelogenin is expressed from both $\mathrm{X}$ and $\mathrm{Y}$ chromosomes, although the level of expression of AMELY is roughly $10 \%$ of that of AMELX [7]. The protein coding regions, exons $2-6$, of the gene are highly conserved $[6,7]$.

The PCR products of AMELX and AMELY can be discriminated from one another using primers flanking a $6 \mathrm{bp}$ deletion in the third intron of AMELX that is not present in AMELY [5,8-10]. The most commonly used amelogenin primer sets are those designed by Sullivan et al., producing AMELX/AMELY amplicons of 106/112 bp and 212/218 bp, respectively (Figure $3 \mathrm{a}$ (included as supplementary data); Table 2) $[9,10]$. After amplification of the AMEL locus, if only the shorter AMELX fragment is observed, this indicates that the DNA donor is an individual with only $\mathrm{X}$ chromosomes, who will usually display a female phenotype. If fragments of both lengths are observed, the DNA donor possesses both $\mathrm{X}$ and $\mathrm{Y}$ chromosomes, which typically predicts a male phenotype. This length variation in the $\mathrm{X}$ and $\mathrm{Y}$ homologues of the amelogenin gene is the basis of the use of amelogenin to determine the sex of a DNA donor in forensic analysis. Since both X and Y specific fragments can be amplified in a single reaction, the amplification of AMELX serves as an internal positive control, which should always be present. Alternative primer sets (Figure 3a (included as supplementary data); Table 2) flanking the same $6 \mathrm{bp}$ deletion and producing an AMELY amplicon $6 \mathrm{bp}$ larger than the AMELX amplicon have been successfully used to 

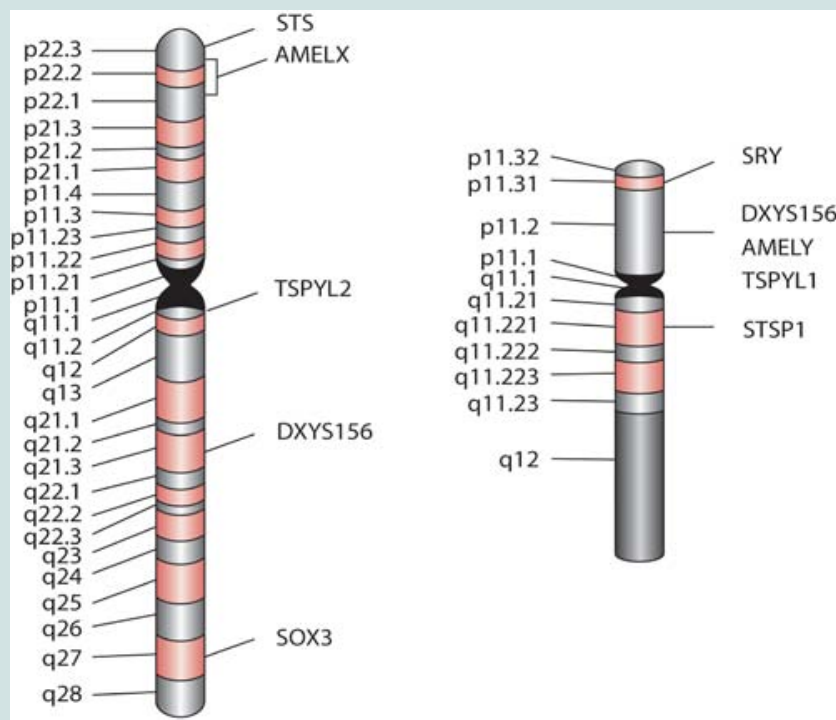

Figure 1: Cytogenetic map of the human $X$ (left) and $Y$ (right) chromosomes with sex typing marker locations. Cytogenetic patterns with alternating dark and light bands are shown.

Table 1: Summary of forensic sex typing markers.

\begin{tabular}{|c|c|c|c|c|}
\hline \multicolumn{7}{|c|}{ Sex typing markers and homologous genes on human X and Y chromosomes } \\
\hline & X Chromosome & & \multicolumn{2}{c|}{ Y Chromosome } \\
\hline Gene Symbol & $\begin{array}{c}\text { Chromosomal } \\
\text { Location }\end{array}$ & Distance from Xpter (Mb) & Gene Symbol & $\begin{array}{c}\text { Chromosomal } \\
\text { Location }\end{array}$ \\
\hline AMELX & Xp22.2 & 11.3 & AMELY & Yp11.2 \\
\hline DXYS156 & Xq21.31 & 88.9 & DXYS156 & Yp11.2 \\
\hline SOX3 & Xq27.1 & 139.6 & SRY & Yp11.31 \\
\hline STS & Xp22.31 & $7.1-7.3$ & STSP1 & Yq11.221 \\
\hline TSPYL2 & Xp11.2 & TSPY1 & 17.7 \\
\hline
\end{tabular}

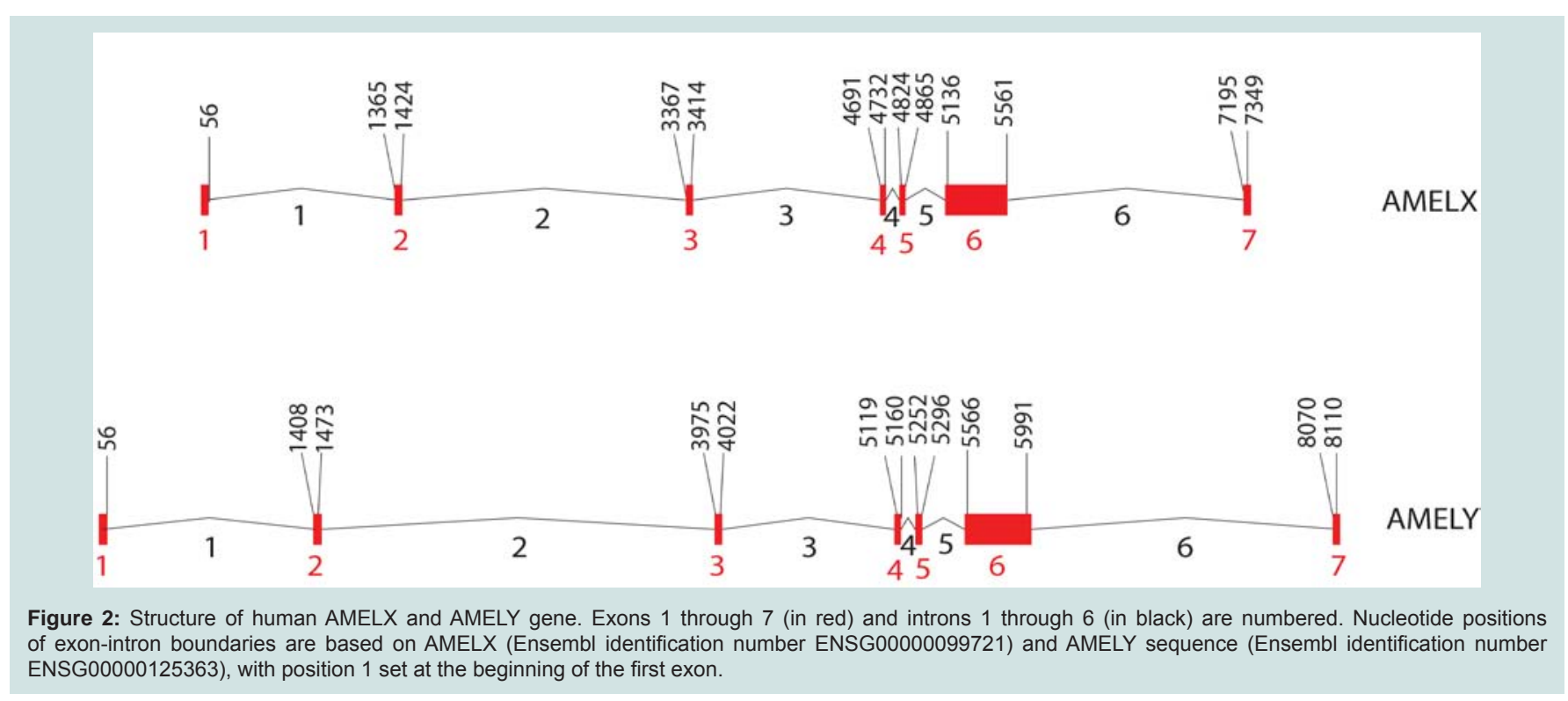

discriminate between the AMELX and AMELY loci [11-13]. See Figure 3a-3c (included as supplementary data) and Table 2 for a detailed list of AMEL primer sets.
The amelogenin test of degraded DNA samples: Primer sets that yield small amplicons have potential application for optimizing a sex determination method for degraded DNA. Haas-Rochholz 
Table 2: Summary of primers used for detecting length polymorphisms of AMELX and AMELY.

\begin{tabular}{|c|c|c|c|c|c|c|c|c|c|c|}
\hline \multicolumn{2}{|c|}{$\begin{array}{c}\text { Polymorphism } \\
\text { AMELX and AMELY }\end{array}$} & \multirow{2}{*}{\multicolumn{2}{|c|}{ Primer Sequence }} & \multirow{2}{*}{$\begin{array}{l}\text { 5' End } \\
\text { Position } \\
\text { at AMELX }\end{array}$} & \multirow{2}{*}{$\begin{array}{l}\text { 3' End } \\
\text { Position } \\
\text { at AMELX }\end{array}$} & \multirow{2}{*}{$\begin{array}{c}5^{\prime} \text { End } \\
\text { Position } \\
\text { at AMELY }\end{array}$} & \multirow{2}{*}{$\begin{array}{c}\text { 3' End } \\
\text { Position } \\
\text { at AMELY }\end{array}$} & \multirow{2}{*}{$\begin{array}{l}\text { AMELX } \\
\text { Amplicon } \\
\text { (bp) }\end{array}$} & \multirow{2}{*}{$\begin{array}{l}\text { AMELY } \\
\text { Amplicon } \\
\text { (bp) }\end{array}$} & \multirow{2}{*}{ Reference } \\
\hline Location & $\begin{array}{l}\text { Length } \\
\text { (bp) }\end{array}$ & & & & & & & & & \\
\hline \multirow{17}{*}{ Intron 3} & \multirow{12}{*}{6} & Forward & 5' -GTCTCTYYTAATGTKAACAATTGCAT-3' & 3253 & 3278 & 3861 & 3886 & \multirow{2}{*}{321} & \multirow{2}{*}{327} & \multirow{2}{*}[12]{$^{* *}$} \\
\hline & & Reverse & 5' -CCAACCATCAGAGCTTAAACTG-3' & 3573 & 3552 & 4187 & 4166 & & & \\
\hline & & Forward & 5'-ACCACCTCATCCTGGGCAC-3' & 3369 & 3387 & 3977 & 3984 & \multirow{2}{*}{281} & \multirow{2}{*}{287} & [11] \\
\hline & & Reverse & 5'-TTACGGCCATATTTAGGA-3' & 3649 & 3632 & 4263 & 4255 & & & [13] \\
\hline & & Forward & 5'-ACCACCTCATCCTGGGCAC-3' & 3369 & 3387 & 3977 & 3995 & \multirow{2}{*}{219} & \multirow{2}{*}{225} & \multirow{2}{*}{ [11] } \\
\hline & & Reverse & 5'-ACACAGGCTTGAGGCCAACC-3' & 3587 & 3568 & 4201 & 3982 & & & \\
\hline & & Forward & 5'-ACCTCATCCTGGGCACCCTGG-3' & 3372 & 3392 & 3980 & 4000 & \multirow{2}{*}{212} & \multirow{2}{*}{218} & \multirow{2}{*}{ [9] } \\
\hline & & Reverse & 5'-AGGCTTGAGGCCAACCATCAG-3' & 3583 & 3563 & 4197 & 4177 & & & \\
\hline & & Forward & 5'-GGCACCCTGGTTATATCAACTTCA-3' & 3383 & 3406 & 3991 & 3914 & \multirow{2}{*}{187} & \multirow{2}{*}{193} & \multirow{2}{*}[12]{$^{* *}$} \\
\hline & & Reverse & 5'-CCATCAGAGCTTAAACTGGGAAGC-3' & 3569 & 3546 & 4183 & 4159 & & & \\
\hline & & Forward & 5'-CCCTGGGCTCTGTAAAGAA-3' & 3462 & 3480 & 4070 & 4088 & \multirow{2}{*}{106} & \multirow{2}{*}{112} & \multirow{2}{*}{ [9] } \\
\hline & & Reverse & 5'-ATCAGAGCTTAAACTGGGAAGCTG-3' & 3567 & 3544 & 4181 & 4158 & & & \\
\hline & 180 & Reverse & 5'-GCTCTGGTACCACTTCA-3' & 4853 & 4837 & 5281 & 5265 & 1487 & 1307 & [b] \\
\hline & & Forward & 5'-CTGATGGTTGGCCTCAAGCCCTGGT-3' & 3563 & 3582 & 4177 & 4196 & & & \\
\hline & 187 & Reverse & 5'-TAAAGAGATTCATTAACTTGACTC-3' & 4539 & 4517 & 4966 & 4944 & 971 & 790 & [8] \\
\hline & $*$ & Forward & 5'-ACCACCTCATCCTGGGCAC-3' & 3369 & 3387 & 3977 & 3984 & $*$ & & {$[11]$} \\
\hline & & Reverse & 5'-GAAAGAGTCAATCCGAATGGT-3' & * & & 4244 & 4224 & & 268 & [13] \\
\hline & & Forward & 5'ACCCCTTTGAAGTGGTACCAGAGCAT-3' & 4830 & 4855 & 5258 & 5283 & 55 & 58 & [15] \\
\hline Exon 5 & 3 & Reverse & 5'-GAACAAAATGTCTACATACYGGTGG-3' & 4884 & 4860 & 5315 & 5287 & 55 & 58 & [15] \\
\hline Exon 5 & 3 & Forward & 5'-CCCTTTGAAGTGGTACCAGAGCA-3' & 4832 & 4854 & 5260 & 5282 & 80 & 83 & [14] \\
\hline & & Reverse & 5'-GCATGCCTAATATTTTCAGGGAATA-3' & 4911 & 4887 & 5342 & 5318 & 80 & 83 & [14] \\
\hline Intron 6 & 1 & Forward & 5'-ATTGAATCCCAAGTAATC-3' & 6643 & 6660 & 7401 & 7418 & 14 & 15 & [17] \\
\hline intron 0 & 1 & Reverse & 5'-GACTAGAATAGCCAATGAT-3' & 6686 & 6668 & 7445 & 7427 & 44 & 40 & {$[17]$} \\
\hline
\end{tabular}

Nucleotide Positions are based on AMELX sequence (Ensembl identification number ENSG00000099721) and AMELY (Ensembl identification number ENSG00000125363), with position 1 set at the beginning of the first exon.

*AMELY specific primer; **Primers used for nested PCR

and Weiler developed a primer set flanking a 3 bp deletion in exon 5 of AMELX (Figure 3d (included as supplementary data); Table 2), producing 80 and 83 bp amplicons for AMELX and AMELY respectively [14]. Codina et al. designed a pair of primers targeting the same $3 \mathrm{bp}$ length polymorphism but which resulting in 55 and 58 bp amplicons for AMELX and AMELY, respectively [15]. They successfully amplified target sequences of artificially degraded DNA using these primers [15].

The use of pyrosequencing techniques for sex typing degraded DNA has also been explored. The pyrosequencing method developed by Tschentscher et al. targets the 3 bp length polymorphism in exon 5, and resulted in clear and reproducible sex typing of DNA samples extracted from buried bone that had failed to amplify with conventional STR kits [16]. Li et al. reported a pyrosequencing method using primers that target a 44/45 bp sequence in intron 6 of AMELX/AMELY that includes a single base pair deletion (Figure $3 \mathrm{e}$ (included as supplementary data); Table 2) on AMELX as well as 3 single nucleotide polymorphism (SNP) differences between AMELX and AMELY sequences for more robust identification [17]. With this method eight samples of degraded DNA from exposed blood stains and four samples of DNA extracted from bone were correctly typed as male or female [17].

Gibbon et al. developed a nested primer system surrounding the 6 bp deletion in intron 3 that was able to detect the presence or absence of Y-specific DNA in archaeological skeletons [12].
Kim et al. describe a real-time PCR method to address dropout of the AMELY allele in degraded DNA [18]. The method uses real-time PCR to identify samples in which allelic dropout, due to stochastic variation in small quantities of DNA, is more likely, therefore allowing for more accurate sex typing of degraded samples [18].

The effects of mutations at amelogenin loci on sex typing: The usefulness of the amelogenin marker in forensics has been repeatedly called into question, as many cases of the failure of the amelogenin marker to correctly determine the sex of DNA donors have been reported [11,13,19-36]. The failure of AMELY to amplify results in an apparent lack of Y-DNA when, in fact, a Y chromosome is present. The reported failure rate for the amelogenin sex test varies by population, ranging from as low as $0.018 \%$ to as high as $8 \%$, with the highest frequencies of amelogenin failure occurring in populations originating from the Indian subcontinent (Table 3) [11,13,19,21,2330,32-36].

Most reported amelogenin test failures are due to large scale deletion events on Yp that include the entirety of AMELY [11,19,21,22,24,27-31,33-35,38]. Several studies have attempted to map the size and location of these deletions, and the majority of reported sizes fall between 1.0 Mb and 3.8 Mb [19,21,24,27-30,34-39]. However, the selection of different markers for mapping the location of deletion breakpoints make comparisons between studies difficult (Table 4). Several studies have localized deletion breakpoints to TSPY (testis-specific protein, $\mathrm{Y}$-encoded) repeat arrays located proximal and distal to AMELY, which has led to the proposal of non-allelic 
Citation: Butler E, Li R. Genetic Markers for Sex Identification in Forensic DNA Analysis. J Forensic Investigation. 2014;2(2): 10.

ISSN: 2330-0396

Table 3: Frequency of AMELY null in different populations.

\begin{tabular}{|c|c|c|c|c|c|}
\hline Population & Frequency (\%) & Sample Size & \multicolumn{2}{|c|}{ 95\% Confidence Interval (\%) } & Ref. \\
\hline Australia & 0.020 & 109000 & 0.0126 & 0.0306 & [24] \\
\hline Austrians & 0.018 & 28182 & 0.0058 & 0.0414 & {$[11]$} \\
\hline Bhutan & 0.000 & 856 & 0.0000 & 0.4300 & {$[25,26]$} \\
\hline Chinese & 0.037 & 8087 & 0.0077 & 0.1084 & {$[32]$} \\
\hline Chinese & 0.023 & 79304 & 0.0135 & 0.0359 & {$[34]$} \\
\hline Chinese & 0.039 & 12915 & 0.0126 & 0.0903 & [35] \\
\hline India & 0.235 & 4257 & 0.1127 & 0.4316 & [13] \\
\hline India & 1.852 & 270 & 0.6040 & 4.2685 & [21] \\
\hline Israel & 1.042 & 96 & 0.0264 & 5.6675 & [23] \\
\hline Italy & 0.008 & 13000 & 0.0002 & 0.0429 & {$[36]$} \\
\hline Japan & 0.200 & 500 & 0.0051 & 1.1092 & {$[30]$} \\
\hline Malaysian Indians & 3.175 & 315 & 1.5326 & 5.7606 & \multirow[t]{2}{*}{ [29] } \\
\hline Malaysian Malays & 0.599 & 334 & 0.0726 & 2.1462 & \\
\hline Nepal & 1.170 & 769 & 0.5365 & 2.2100 & {$[26]$} \\
\hline Nepal & 6.494 & 77 & 2.1419 & 14.5067 & {$[28]$} \\
\hline Singapore Chinese & 0.000 & 210 & 0.0000 & 1.7413 & \multirow{3}{*}[27]{} \\
\hline Singapore Indian & 1.714 & 175 & 0.3549 & 4.9279 & \\
\hline Singapore Malay & 0.549 & 182 & 0.1391 & 3.0232 & \\
\hline Sri Lanka & 8.333 & 24 & 1.0256 & 26.9973 & [19] \\
\hline
\end{tabular}

Confidence intervals are calculated based on a binomial distribution and therefore are not symmetrical around the reported values. AMELY null rates are very small, and binomial confidence limits more accurately account for the impossibility of a population frequency that is less than zero or, in a population that has at least one reported AMELY null case, that is equal to zero.

Table 4: Summary of published data on Yp deletions that include the amelogenin locus.

\begin{tabular}{|c|c|c|c|c|}
\hline $\begin{array}{l}\text { Deletion Size } \\
\text { (Mb) }\end{array}$ & Breakpoint Locations & $\begin{array}{c}\text { Number } \\
\text { of AMELY } \\
\text { Null }\end{array}$ & Mapping Method & Ref. \\
\hline- & TSPYB (minor array), TSPYA (major array) & 2 & 37 Y-specific loci tested by hybridization or PCR & [19] \\
\hline $0.3-0.7$ & $6.7 \mathrm{Mb}, 7.4 \mathrm{Mb}$ & 2 & 8 Y-specific STS markers & [24] \\
\hline $0.7-1.0$ & $6.7 \mathrm{Mb}, 7.4-7.7 \mathrm{Mb}$ & 3 & 8 Y-specific STS markers & [24] \\
\hline 1 & - & 5 & 6 Y-STRs, Southern hybridization & {$[21]$} \\
\hline $1.13^{\mathrm{a}}$ & AMELY, DYS458 & 18 & 16 Y-STRs & [29] \\
\hline $1.18^{\mathrm{b}}$ & AMELY, DYS458 & 8 & 16 Y-STRs & [34] \\
\hline- & AMELY, DYS458 & 1 & 17 Y-STRs & [32] \\
\hline $1.51-2.58$ & $5.42-6.44,7.97-7.99$ & 1 & 17 Y-STRs and 23 Y specific STS markers & [39] \\
\hline 2.3 & $6.443 \mathrm{Mb}, 8.75 \mathrm{Mb}$ & 5 & 19 Y-specific STS and SNP markers & [28] \\
\hline 2.43 & $6.74 \mathrm{Mb}, 9.17 \mathrm{Mb}$ & 2 & 77 Y-specific STS markers & [35] \\
\hline $2.5-3.1$ & $4.5-5.0 \mathrm{Mb}, 7.5-7.6 \mathrm{Mb}$ & 1 & 33 Y-specific STS markers & [37] \\
\hline 2.51 & $6.44 \mathrm{Mb}, 8.95 \mathrm{Mb}$ & 1 & 60 loci including Y-STRs and Y-specific STSs & [30] \\
\hline 2.56 & $6.67 \mathrm{Mb}, 9.23 \mathrm{Mb}$ & 4 & 7 Y-specific STS markers and 6 Y-STRs & [38] \\
\hline $3.0-3.8$ & $6.2 \mathrm{Mb}, 9.2-10.0 \mathrm{Mb}$ & 41 & 33 Y-specific STS markers & [37] \\
\hline 3.38 & $6.73 \mathrm{Mb}, 10.11 \mathrm{Mb}$ & 1 & 16 Y-STRs & {$[34]$} \\
\hline $3.35-3.87$ & $4.31-4.71,8.06-8.12$ & 1 & 23 Y specific STS markers & [39] \\
\hline $3.5-3.9$ & $3.65-4.0 \mathrm{Mb}, 7.5 \mathrm{Mb}$ & 2 & 33 Y-specific STS markers & [37] \\
\hline
\end{tabular}




\begin{tabular}{|l|l|c|l|}
\hline $\begin{array}{c}\text { Deletion Size } \\
(\mathbf{M b})\end{array}$ & \multicolumn{1}{|c|}{ Breakpoint Locations } & $\begin{array}{c}\text { Number } \\
\text { of AMELY } \\
\text { Null }\end{array}$ & \multicolumn{1}{|c|}{ Mapping Method } \\
\hline 3.6 & DYS456, DYS458 & 1 & 17 Y-STRs \\
\hline 3.6 & $4.31 \mathrm{Mb}, 7.91 \mathrm{Mb}$ & 1 & 16 Y-STRs \\
\hline 3.7 & $6.2 \mathrm{Mb}$ (TSPYB), 9.9 Mb (TSPYA) & & 12 Y-specific STS markers and 3 Y-STRs \\
\hline $3.9-4.0$ & $3.6 \mathrm{Mb}, 7.5-7.6 \mathrm{Mb}$ & 1 & 33 Y-specific STS markers \\
\hline 4.69 & $3.6 \mathrm{Mb}, 8.29 \mathrm{Mb}$ & 1 & 77 Y-specific STS markers \\
\hline
\end{tabular}

Breakpoint locations listed in Mb are distance from Ypter. Since studies used different markers, it is difficult to make direct comparisons between the findings, however there are some general commonalities in location and size of deletions across studies.

a Minimum possible size of deletion based on locations of AMELY and DYS458 mapped in study [29].

b Minimum possible size of deletion based on locations of AMELY and DYS458 listed by study [34].

"-" indicates no data.

homologous recombination between TSPY repeats as the mechanism for some Yp deletions $[19,27,37]$. The structure and location of TSPY repeat arrays are discussed in more detail in a subsequent section.

A primer binding site mutation in AMELY has been theorized as the cause of instances of failure of amplification of AMELY [20,34]. However, there is no sequencing data available for these samples, nor are there any reports of successful amplification of an AMELY null sample with alternate primers.

Amelogenin sex test failures involve failure of AMELY to amplify, which results in the incorrect identifying of DNA samples from phenotypic males as female. However, other complicating factors in the use of the amelogenin test have been documented. Cases of a mutation in the primer binding region of AMELX leading to lack of amplification of AMELX have also been reported [32,40,41]. While failure of AMELX to amplify will not lead to incorrect sex typing, it can complicate the interpretation of DNA mixtures using the relative amounts of AMELX and AMELY amplicons. One case of related phenotypic females who typed as XY with the amelogenin test has also been reported [42]. These individuals possessed a small quantity of Y-specific DNA encompassing the amelogenin locus on an $\mathrm{X}$ chromosome [42].

In addition, several instances of amelogenin test failure have been reported in which the translocation of sex-determining region $\mathrm{Y}$ (SRY) to the X chromosome has caused the development of male reproductive organs and secondary sex characteristics in individuals with an XX karyotype [11,15,31,34,35]. These individuals do not have a Y chromosome and therefore do not have the AMELY marker, or any Y-specific markers other than SRY, which is discussed in more detail in following section.

\section{Other Sex Typing Markers}

\section{SRY}

Sex-determining region $\mathrm{Y}$ (SRY) is located on the Y chromosome at $\mathrm{p} 11.31$ within a $35 \mathrm{~kb}$ sex-determining region of the $\mathrm{Y}$ chromosome adjacent to the pseudoautosomal region (Figure 1; Table 1). SRY encodes a transcription factor that is a member of the high mobility group (HMG)-box family of DNA binding proteins and contains the conserved DNA-binding motif indicative of HMG proteins $[43,44]$. $\mathrm{Su}$ and Lau found that human SRY is an intronless gene [45]. The coding region of SRY is 845 bp long. SOX3 (Figure 1; Table 1), an SRY-related HMG-box containing gene, has been identified on the $\mathrm{X}$ chromosome at q27.1 and shares sequence homology with SRY [46].
The SRY gene has been shown to be integral to the development male reproductive organs [47]. As such, it is the only sex typing marker currently in use whose gene products directly affect biological sex development. In contrast, the three of the other markers detailed in later sections have only an indirect relationship with physical indicators of male sex, in that they are present on Y-specific regions of the $\mathrm{Y}$ chromosome but do not have gene products that play any role in human sexual dimorphism. The testis-specific protein (TSPY) locus, which is discussed in detail in a subsequent section, may play a role in spermatogenesis, however the exact relationship is not yet clear and no currently available data suggests as strong a causal link to male sex development as SRY.

The strong association of the products of SRY with male phenotype means that SRY is the most accurate available marker for prediction of male appearance and is often used as a confirmatory test when an amelogenin test produces unexpected results $[11,48,49]$. Steinlechner et al. used primer sequences targeting a section of the non-coding region of SRY (Figure 4; Table 5) to successfully resolve a case in which a sample from a phenotypic male failed to amplify both AMELY and a set of eight Y-STR markers [11,50]. The translocation of SRY to the X chromosome was proposed as a possible explanation for the presence of SRY but no AMELY or any of 8 Y-STRs in this individual [11]. Tozzo et al. proposed a duplex amplification using AMEL primers concurrently with primers targeting a $197 \mathrm{bp}$ portion of SRY for accurate sex typing (Figure 4; Table 5), and successfully used this method to correctly type an AMELY-deleted sample from a phenotypic male [48]. The use of an SRY fragment in concert with the standard AMEL X and Y markers allows for both the comparison of $\mathrm{X}$ and $\mathrm{Y}$ homologues and the use of an $\mathrm{X}$ allele as an internal control, while also decreasing the probability of assigning sex incorrectly in the case of an AMELY deletion.

Drobnic reported successful amplification of a marker residing in the SRY gene which results in a 96 bp long PCR product (Figure 4; Table 5) that, due to its short length, can be easily incorporated into existing identification kits $[49,51]$. A PCR multiplex (Genderplex) developed by Codina et al. amplifies two different regions of the amelogenin gene together with a $93 \mathrm{bp}$ sequence (Figure 4; Table 5) of SRY and four mini X-STR loci with high levels of heterozygosity, allowing for redundancy in male sex assignment with the SRY amplicon supported by a homozygous genotype at X-STR loci [15]. A female DNA profile would be confirmed not only by the absence of SRY but also by expected heterozygosity in at least one of the 4 X-STRs [15]. 


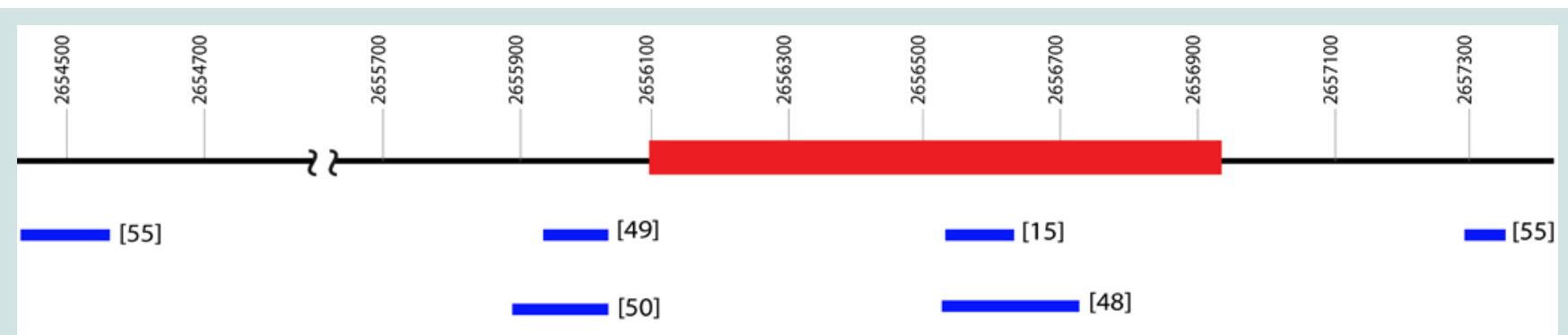

Figure 4: Physical locations of amplicons using different primers at SRY locus(Ensembl identification number ENSG00000184895.6). The physical locations are based on the distance from Ypter (bp). Exon (red box) as well as 5' and 3' sequences (black lines) are shown. Amplicons (blue boxes) are shown with their reference in brackets.Additional information about the primers can be found in Table 5 .

Table 5: Summary of primers used to amplify the SRY locus.

\begin{tabular}{|c|c|c|c|}
\hline \multicolumn{2}{|r|}{ Primer Sequence } & $\begin{array}{l}\text { Amplicon } \\
\text { Size (bp) }\end{array}$ & Ref. \\
\hline Forward & 5'AGCCCCTGTGGAAAAAATTAGTTTT-3' & \multirow[b]{2}{*}{77} & \multirow[b]{2}{*}{ [55] } \\
\hline Reverse & $\begin{array}{l}\text { 5'-AAAACACCATAGTTTTATATGGAGTA- } \\
\text { AAGGAAC-3' }\end{array}$ & & \\
\hline Forward & 5'-GAGTGAAGCGACCCATGAAC-3' & \multirow{2}{*}{85} & \multirow{2}{*}[52]{$^{a}$} \\
\hline Reverse & 5'-TTTCGCATTCTGGGATTCTC-3' & & \\
\hline Forward & 5'-AGGCACAGAAATTACAGGCCATGC-3' & \multirow{2}{*}{93} & \multirow{2}{*}{ [15] } \\
\hline Reverse & 5'-TGCAATTCTTCGGCAGCATCTTCG-3' & & \\
\hline Forward & 5'-AGCAGTCAGGGAGGCAGATCA-3' & \multirow{2}{*}{96} & \multirow{2}{*}{ [49] } \\
\hline Reverse & 5'-CCCCCTAGTACCCTGACAATGTAT T-3' & & \\
\hline Forward & 5'-AGGCAACTGCCAGGATAGAG-3' & \multirow{2}{*}{102} & \multirow{2}{*}[52]{$^{a}$} \\
\hline Reverse & 5'-TTTCGCATTCTGGGATTCTC-3' & & \\
\hline Forward & 5'-TTGTGCAGCCATCACCTCT-3' & \multirow{2}{*}{130} & \multirow{2}{*}{ [55] } \\
\hline Reverse & 5'AAATCAGATTAATGGTTGCT-3' & & \\
\hline Forward & 5'-TGGCGATTAAGTCAAATTCGC-3' & \multirow{2}{*}{137} & \multirow{2}{*}[50]{} \\
\hline Reverse & 5'-CCCCCTAGTACCCTGACAATGTAT T-3' & & \\
\hline Forward & 5'-TCCAGGAGGCACAGAAATTA-3' & \multirow{2}{*}{197} & \multirow{2}{*}{ [48] } \\
\hline Reverse & 5'-TCTTGAGTGTGTGGCTTTCG-3' & & \\
\hline Forward & 5'-CGGAGAAGCTCTTCCTTCCT-3' & \multirow{2}{*}{198} & \multirow{2}{*}[52]{$^{\mathrm{b}}$} \\
\hline Reverse & 5'-CAGCTGCTTGCTGATCTCTG-3' & & \\
\hline
\end{tabular}

The short length (96 and $93 \mathrm{bp}$ ) of the SRY amplicons demonstrated in the above studies facilitates the inclusion of the SRY locus in existing kits, since SRY PCR products can be electrophoretically separated from any AMEL or STR alleles in current multiplex kits. Short amplicons are also advantageous for sex determination of degraded DNA. Luptáková et al. used primers for short length SRY amplicons specifically to determine the sex of ancient skeletal remains. Nested primer pairs for SRY resulted in 102 and 85 bp amplicons (Figure 4; Table 5), while the X chromosome microsatellite DXZ4 served as a control [52]. DXZ4 is a polymorphic tandem array on the $\mathrm{X}$ chromosome consisting of $3 \mathrm{~kb}$ units with between 12 and 100 copies $[53,54]$. Successful amplification was obtained in 23 of 25 sets of remains tested, however dropout of the single-copy gene SRY while the multi-copy DXZ4 remained detectable may have resulted the mistyping of 2 sets of remains [52].

The method proposed by Morikawa et al. uses a multiplex amplification of SRY, STS (steroid sulfatase; see subsequent section) and amelogenin and their homologous sequences [55]. Two primer sets were used to amplify 77 and $130 \mathrm{bp}$ regions of SRY (Figure 4; Table 5). Each of these SRY primer sets also amplifies a homologous sequence, one on the $\mathrm{X}$ chromosome and one on chromosome 7 , providing the amplification of SRY with its own internal controls [55]. When DNA obtained from an AMELY-deleted male donor was amplified, the AMELY peak was absent but peaks for both SRY amplicons, as well as their $\mathrm{X}$ and 7 chromosome counterparts, were present [55]. This method is unique in that it proposes primers for SRY that also amplify sequences on non-Y chromosomes for use as internal controls. The other methods detailed here, in contrast, use unrelated X chromosome sequences with independent primers to verify amplification, which can potentially lead to mistyping when there are differences in amplification, as noted in the results of Luptáková et al. described above [52].

The direct link of the gene products of SRY with male development makes SRY a powerful marker for sex typing in a variety of applications, including forensics. Of current and potential sex typing markers described here, SRY is possibly the most accurate predictor of male biological sex. However, its use is complicated by the lack of a highly homologous X chromosome sequence that can be amplified concurrently, although some possibilities in this direction have recently been explored [55].

\section{TSPY}

Y-encoded testis-specific protein (TSPY) is restricted to testicular tissue and may play a role in spermatogenesis, as there is some evidence of a link between TSPY copy number and sperm concentration [5661]. TSPY is a Y-specific, heterogeneous gene family located primarily on human Yp11.2, although some copies exist on Yq (Figure 1; Table 1) [62-64]. The TSPY structural gene consists of 6 exons and 5 introns and gives rise to a pool of heterogeneously composed transcripts, one of which, TSPY1, results in a protein that is a member of a super protein family along with protooncogene SET and nucleosome 
assembly factor NAP1, which are activating factors of the replication process [57]. TSPY was originally defined by the genomic probe DYS14 which is located in intron 1 of TSPY $[57,62,65]$.

Multiple TSPY sequences have been shown to be constitutive parts of a Y-specific tandemly-repeated array, consisting of multiple homogenous $20.4 \mathrm{~kb}$ repeat units, also known as the DYZ5 locus $[62,66]$. DYZ5 has been used as a hybridization probe for Southern blot and FISH mapping of TSPY units on to the Y chromosome. These repeat units encode TSPY on one strand and a pseudogene transcription unit CYorf16 on the complimentary strand [67]. One large TSPY array is found on proximal Yp, while a smaller repeat array is located more distally [66,67]. This is an unusual structure in the human genome, as the vast majority of protein coding genes are not present in tandem clusters of more than 3 units [66]. The number of copies of TSPY present varies on an interindividual basis. Researchers have reported TSPY copy numbers ranging from 11 to 110, although copy numbers in the range of 20-60 are more common $[58,65,68,69]$. Non-allelic homologous recombination between TSPY copies may be responsible for at least one type of AMELY deletion, and individuals having this deletion also show a reduced copy number of TSPY repeats when compared to AMELY positive individuals [19,27,37]. Due to the high individual variation, TSPY copy number cannot be used to estimate the size of the deletion.

A TSPY-like (TSPYL) gene has been identified on the short arm of the X chromosome and designated TSPYL2 (Figure 1; Table 1). TSPYL2 exists in only a single copy per X chromosome and is $6.3 \mathrm{~kb}$ in length, consisting of 7 exons and 6 introns [70]. TSPYL2 shares homology with TSPY [70]. Additionally, several TSPYL genes have been identified on autosomal chromosomes. Primers can be designed to amplify TSPY only and not TSPYL2 or other TSPYL genes.

The high copy number of TSPY affords a level of sensitivity in detecting Y-chromosome specific DNA that could be advantageous in untangling mixtures of male and female DNA is cases of sexual assault [71-75]. The primers used in TSPY assays are described in Table 6. Kamodyova et al. found that a TSPY assay could detect male DNA in saliva samples collected from women after intense kissing with a male partner up to 60 minutes after kissing, while an SRYbased assay detected male DNA at most 10 minutes after kissing [71]. Jacot et al. showed that amplification of the TSPY4 marker can detect male DNA in much lower concentrations than the single-copy SRY marker. This allows for detection of a small quantity of male DNA in a mixture with much larger concentration of female DNA, as well as detection of male DNA from vaginal swabs 72 hours post semen exposure in all cases, and as long as 7 days post semen exposure in one case [74]. Campos et al. detected TSPY in 5 out of 10 samples of vaginal swabs of rape victims, while SRY could be detected in only 3 , and prostate specific antigen (PSA) in only 2 samples [75]. The sensitivity of the TSPY marker has clear advantages in analysis of forensic samples [76]. Benoit et al. used a TSPY-specific primer set to successfully amplify Y-specific DNA from ancient and weathered bone fragments, using autosomal Alu and mitochondrial sequences as internal controls [77].

The TSPY locus is unique among the markers discussed here because of the high number of TSPY repeats present on the Y chromosome. The potential for developing extremely sensitive
Table 6: Summary of primers used to amplify TSPY locus.

\begin{tabular}{|c|c|c|c|}
\hline \multicolumn{2}{|r|}{ Primer Sequence } & $\begin{array}{l}\text { Am- } \\
\text { plicon }\end{array}$ & Ref. \\
\hline Forward & 5' - GGGCCAATGTTGTATCCTTCTC - 3' & \multirow{3}{*}{84} & \multirow{2}{*}{$\begin{array}{c}{[69} \\
71,72] \\
{[75]^{\mathrm{b}}}\end{array}$} \\
\hline Reverse & 5' - GCCCATCGGTCACTTACACTT C - 3' & & \\
\hline Probe $^{a}$ & 5' - TCTAGTGGAGAGGTGCTC - 3' & & $\begin{array}{c}{[69} \\
71,72]\end{array}$ \\
\hline Forward & $\begin{array}{l}\text { 5' - GCT ATT GAG TTG TTG GGA GTT CCT } \\
\text { T - 3' }\end{array}$ & \multirow{3}{*}{137} & \multirow{3}{*}[76,77]{} \\
\hline Reverse & $\begin{array}{l}\text { 5'- AAG TGC TTC ACC ACA CCA TGA AAA } \\
- \text { 3' }\end{array}$ & & \\
\hline Probe $^{a}$ & 5' - CTGTGACTATTCCC - 3' & & \\
\hline Forward & 5'-TGG GCC CAT GAC CCC AGA GT - 3' & \multirow{2}{*}{138} & \multirow{2}{*}[74]{} \\
\hline Reverse & 5'-TCT AGG TGG GGC TTG CGC CT - 3' & & \\
\hline Forward & 5' - CATCCAGAGCGTCCCTGG - 3' & \multirow{3}{*}{147} & \multirow{3}{*}{ [73] } \\
\hline Reverse & 5' - TTCCCCTTTGTTCCCCAAA - 3' & & \\
\hline Probe $^{\mathrm{a}}$ & 5' - AGCACCTCTCCACTAGAAAGGC - 3' & & \\
\hline Forward & 5' - CATCCAGAGCGTCCCTGGCTT - 3' & \multirow{2}{*}{198} & \multirow{2}{*}[75]{$^{\mathrm{b}}$} \\
\hline Reverse & 5' - CTTTCCACAGCCACATTTGTC - 3' & & \\
\hline Forward & $\begin{array}{l}\text { 5' - CGGGGAAGTGTAAGTGACCGATGGG } \\
-3^{\prime}\end{array}$ & \multirow{3}{*}{213} & \multirow{3}{*}{ [59] } \\
\hline Reverse & 5' - CTGCTCTTCAAAAAGATGCCCCAAA - 3' & & \\
\hline Probe $^{\mathrm{a}}$ & sequence not reported & & \\
\hline Forward & $\begin{array}{l}\text { 5' - GAGGTGCTCTCGGGGAAGTGTAAGTG } \\
\text { - 3' }\end{array}$ & \multirow{3}{*}{397} & \multirow{3}{*}{ [59] } \\
\hline Reverse & $\begin{array}{l}\text { 5' - GAGGGTGTATGATTCTGAGGCTGACTG } \\
- \text { 3' }\end{array}$ & & \\
\hline Probe $^{\mathrm{a}}$ & sequence not reported & & \\
\hline Forward & 5' - ATGACCCAATCTGCACT - 3' & \multirow{3}{*}{-} & \multirow{3}{*}{ [68] } \\
\hline Reverse & 5' - CTGGCTTGGGCATTAACC - 3' & & \\
\hline Probe $^{a}$ & sequence not reported & & \\
\hline
\end{tabular}

a probe sequences are included where primer sets are used for quantitative PCR b primers used for nested PCR

"-" indicates no data

TSPY assays for detecting male DNA in female/male mixtures and for accurate sex identification with degraded DNA has been clearly demonstrated. While the possibility of co-amplifying a portion of TSPYL2 alongside TSPY as an X chromosome internal control could be explored further, as a single copy gene the use of TSPYL2 in sensitive assays designed for low copy number or degraded samples may be limited.

\section{DXYS156}

The pentanucleotide STR DXYS156 is present on both X and $\mathrm{Y}$ chromosomes and can be used for sex determination (Figure 1; Table 1). DXYS156 has been localized by linkage analysis to the long arm of the X chromosome and shows sequence homology with the short arm of the Y chromosome [78]. DXYS156 is a multi-allelic STR with a single (TAAAA) ${ }_{n}$ motif in the consensus sequence $[78,79]$. Y chromosome alleles of DXYS156 can be distinguished from X alleles by detecting the presence of a Y-specific adenine insertion in the repeat units [80]. This insertion is consistently located in the fourth repeat motif from the 5' end in $\mathrm{Y}$ chromosome alleles only and allows for $\mathrm{X}$ and $\mathrm{Y}$ alleles to be unambiguously differentiated [80].

Due to high sequence similarity in the regions flanking the repeat units of DXYS156, polymorphisms in this STR can be detected with a single primer pair amplifying both X and Y alleles [79]. The DXYS156 
locus is multi-allelic, with 11 different alleles spread over a range of 4-15 repeats of the (TAAAA) motif [79-82]. DXYS156 is reported as polymorphic in all populations studied and the Y locus displays greater genetic variability than the $\mathrm{X}$ locus [78]. There is also evidence that DXYS156 alleles are demographically restricted and so have the potential to provide information regarding the geographic origin of an individual in forensic cases [80].

These results indicate that the DXYS156 locus may successfully be used for sex identification in forensic cases, particularly in instances of failure of the amelogenin test. The DXYS156 locus, like amelogenin but in contrast to the SRY locus, provides an internal positive control in the $\mathrm{X}$ alleles, which should always be present. Unlike amelogenin, DXYS156 is multi-allelic, which carries the advantages of a higher power of discrimination and the possibility of information regarding geographic origin.

\section{STS}

The STS gene encodes steroid sulfatase, a membrane-bound microsomal enzyme that is ubiquitously expressed and hydrolyzes steroid sulfates, which serve as metabolic precursors for estrogens, androgens, and cholesterol [83]. Deletions and point mutations in the STS gene are associated with X-linked ichthyosis, a skin disease that affects XY individuals $[84,85]$. Cases of both female and male individuals with additional copies of STS have been reported; these copy gains are most likely a benign population variant [86].

The STS gene is located on the X chromosome at p22.31 (Figure 2; Table 1), contains 10 exons and 9 introns, and spans about $146 \mathrm{~kb}$ [87]. The size of each STS exon is between 120 and $160 \mathrm{bp}$, however, the sizes of introns range from $102 \mathrm{bp}$ up to $35 \mathrm{~kb}$. A $100 \mathrm{~kb}$ STS pseudogene is present on Yq, and is designated STSP1 [87] (Figure 1; Table 1). The sequence homology between STS and STSP1 is $84.5 \%$, however, STSP1 does not encode a functional protein [55].

With primer sets that target a $35 \mathrm{~kb}$ sequence in the first intron of STS and its homologous sequence in STSP1, amplicons of two different sizes are produced that allow STS and STSP1 to be identified and used for sex typing purposes. Morikawa et al. demonstrated a multiplex method for sex determination that includes both STS and STSP1, as well as amelogenin X and $\mathrm{Y}$ and two sequences of SRY along with homologous sequences on chromosomes $\mathrm{X}$ and 7 , described above [55]. In the male control DNA both STS and STSP1 were amplified, resulting in two clear peaks, while in the female control DNA only STS was amplified. The amplification of DNA obtained from a AMELY-deleted male donor showed peaks for both STS and the STSP1, demonstrating the potential use of these sequences in developing accurate sex determination methods for forensic DNA analysis [55].

\section{Conclusions}

Although amelogenin has been the workhorse of DNA sex identification for many years, the body of work documenting failures of the amelogenin marker has been accumulating for some time. In the United States, expanding the CODIS core loci has recently been proposed [88]. The proposed expanding CODIS loci include additional autosomal STR loci as well as a Y-STR locus in case amelogenin fails to amplify. Nevertheless, it seems clear that new sex identification methods that meet the rigorous standards required of forensic casework are needed.
The SRY locus is currently the most thoroughly investigated alternative to amelogenin and is already frequently used in addition to or in place of amelogenin for sex typing purposes. SRY has the advantage of being the Y-chromosome marker most closely linked to biological sex and thus its presence is most likely to accurately predict the biological sex of a DNA donor. However, unlike amelogenin, SRY lacks a well-defined homologue on an autosomal or X chromosome that may be amplified with the same primers to act as an internal control for successful amplification. Instead, $\mathrm{X}$ or autosomal sequences amplified with different primer sets are often used alongside SRY amplification to serve as a control. This leaves the potential for undetected SRY dropout and mistyping of XY individuals as XX, a possibility that is markedly increased when only degraded or very small quantities of DNA are available, as is often the case in forensic work.

In contrast to the single copy amelogenin and SRY, TSPY is present is multiple copies per $\mathrm{Y}$ chromosome, resulting in a sensitive marker that can be detected from much smaller amounts of DNA. This sensitivity could potentially be a great boon for future development of TSPY-based assays for determining the sex of highly degraded samples or detecting a very small concentration of male DNA in a male/female mixture.

The microsatellite DXYS156 locus, like amelogenin but in contrast to the SRY locus, maps to both $\mathrm{X}$ and $\mathrm{Y}$ chromosomes with clear differentiation between $\mathrm{X}$ and $\mathrm{Y}$ alleles, providing an easy to use internal positive control. Additionally, DXYS156 is a multi-allelic polymorphic STR maker that can be used for human identification. This characteristic property is unique to the DXYS156 locus compared to other Y-chromosome markers used for sex identification. The advantages of a polymorphic locus include an improved power of discrimination and the possibility of information regarding geographic origin.

The STS locus is located on the $\mathrm{X}$ chromosome, which is different from other markers discussed here. Its Y chromosome counterpart, pseudogene STSP1, can potentially be used for sex typing, and has been shown to amplify successfully in AMELY-deleted male samples.

\section{References}

1. National DNA Index System (NDIS) Operational Procedures Manual, FBI Laboratory, Version 1 Effective January 31, 2013.

2. Von Wurmb-Schwark N, Bosinski H, Ritz-Timme S (2007) What do the X and $Y$ chromosomes tell us about sex and gender in forensic case analysis? J Forensic Leg Med14: 27-30.

3. Wright JT (2006) The molecular etiologies and associated phenotypes of amelogenesis imperfecta. Am J Med Genet A 140: 2547-2555.

4. Nakahori $Y$, Takenaka O, Nakagome $Y$ (1991) A human $X-Y$ homologous region encodes "Amelogenin". Genomics 9: 264-269.

5. Nakahori Y, Hamano K, Iwaya M, Nakagome Y (1991) Sex identification by polymerase chain reaction using $X-Y$ homologous primer. Am J Med Genet 39: 472-473.

6. Sasaki S, Shimokawa H (1995) The amelogenin gene. Int J Dev Biol 39: 127133.

7. Salido EC, Yen PH, Koprivnikar K, Yu LC, Shapiro LJ (1992) The human enamel protein gene amelogenin is expressed from both the $X$ and the $Y$ chromosomes. Am J Hum Genet 50: 303- 316.

8. Akane A, Shiono H, Matsubara K, Nakahori Y, Seki S, et al. (1991) Sex identification of forensic specimens by polymerase chain reaction (PCR): Two alternative methods. Forensic Sci Int 49: 81-88. 
9. Sullivan KM, Mannucci A, Kimpton CP, Gill P (1993) A rapid and quantitative DNA sex test: Fluorescence-based PCR analysis of $X-Y$ homologous gene amelogenin. BioTechniques 15: 640-641.

10. Mannucci A, Sullivan KM, Ivanov PL, Gill P (1994) Forensic application of a rapid and quantitative DNA sex test by amplification of the $X-Y$ homologous gene amelogenin. Int J Legal Med 106: 190-193.

11. Steinlechner M, Berger B, Niederstätter H, Parson W (2002) Rare failures in the amelogenin sex test. Int J Legal Med 116: 117-120.

12. Gibbon V, Paximadis M, Štrkalj G, Ruff P, Penny C (2009) Novel methods of molecular sex identification from skeletal tissue using the amelogenin gene. Forensic Sci Int Genet 3: 74-79.

13. Kashyap VK, Sahoo S, Sitalaximi T, Trivedi R (2006) Deletions in the Y-derived amelogenin gene fragment in the Indian population. BMC Med Genet 7: 37

14. Haas-Rochholz H, Weiler G (1997) Additional primer sets for an amelogenin gene PCR-based DNA-sex test. Int J Legal Med 110: 312-315.

15. Codina AE, Niederstätter H, Parson W (2009) GenderPlex a PCR multiplex for reliable gender determination of degraded human DNA samples and complex gender constellations. Int J Legal Med 123: 459-464.

16. Tschentscher F, Frey UH, Bajanowski T (2008) Amelogenin sex determination by pyrosequencing of short PCR products. Int J Legal Med 122: 333-335.

17. Li S, Feng T, Fu L, Li Z, Lou C et al. (2012) Pyrosequencing of a short fragment of the amelogenin gene for gender identification. Mol Biol Rep 39: 6949-6957.

18. Kim KY, Kwon Y, Bazarragchaa M, Park AJ, Bang H, et al. (2013) A real-time PCR-based amelogenin $Y$ allele dropout assessment model in gender typing of degraded DNA samples. Int J Legal Med 127: 55-61.

19. Santos FR, Pandya A, Tyler-Smith C (1998) Reliability of DNA-based sex tests. Nat Genet 18: 103.

20. Roffey PE, Eckhoff Cl, Kuhl JL (2000) A rare mutation in the amelogenin gene and its potential investigative ramifications. J Forensic Sci 45: 1016-1019.

21. Thangaraj $K$, Reddy AG, Singh $L$ (2002) Is the amelogenin gene reliable for gender identification in forensic casework and prenatal diagnosis? Int J Legal Med 116: 121-123.

22. Brinkmann B (2002) Is the amelogenin sex test valid? Int J Legal Med 116 63.

23. Michael A, Brauner P (2004) Erroneous Gender Identification by the Amelogenin Sex Test. J Forensic Sci 49: 258-259.

24. Mitchell RJ, Kreskas M, Baxter E, Buffalino L, Van Oorschot RAH (2006) An investigation of sequence deletions of amelogenin (AMELY), a Y-chromosome locus commonly used for gender determination. Ann Hum Biol 33: 227-240.

25. Parkin E, Kraayenbrink T, Driem G, Tshering Of Gaselô K, de Knijff $P$, et al (2006) 26-Locus Y-STR typing in a Bhutanese population sample. Forensic Sci Int 161: 1-7.

26. Parkin E, Kraayenbrink T, Robert J, Opgenort M L, Driem G et al. (2007) Diversity of 26-locus Y-STR haplotypes in a Nepalese population sample: Isolation and drift in the Himalayas. Forensic Sci Int 166: 176-181.

27. Yong RYY, Gan LSH, Chang YM, Yap EPH (2007) Molecular characterization of a polymorphic 3-Mb deletion at chromosome Yp11.2 containing the AMELY locus in Singapore and Malaysia populations. Hum Genet 122: 237-249.

28. Cadenas AM, Regueiro M, Gayden T, Singh N, Zhivotovsky LA, et al. (2007) Male amelogenin dropouts: phylogenetic context, origins and implications. Forensic Sci Int 166: 155-163.

29. Chang YM, Perumal R, Keat PY, Yong RYY, Kuehn DLC, et al. (2007) A distinct Y-STR haplotype for Amelogenin negative males characterized by a large Yp11.2 (DYS458-MSY1-AMEL-Y) deletion. Forensic Sci Int 166: 115120

30. Takayama T, Takada N, Suzuki R, Nagaoka S, Watanabe Y, et al. (2009) Determination of deleted regions from Yp11.2 of an amelogenin negative male. Leg Med 11: S578-S580.
31. Zehethofer K, Rolf B (2011) A molecular analysis of three amelogenin negative males in two routine paternity tests. Forensic Sci Int Genet 5: 550551.

32. Ou X, Chen W, Chen H, Zhao F, Zheng J et al. (2012) Null alleles of the X and y chromosomal amelogenin gene in a Chinese population. Int $\mathrm{J}$ Legal Med 126: 513-518.

33. Davis C, Illescas M, Tirado C, Lopez R, Budowle B et al. (2012) A Case of Amelogenin $Y$-null: A simple primer binding site mutation or unusual genetic anomaly? Leg Med 14: 320-323.

34. Ma Y, Kuang JZ, Zhang J, Wang GM, Wang YJ et al. (2012) Y chromosome interstitial deletion induced Y-STR allele dropout in AMELY-negative individuals. Int J Legal Med 126: 713-724.

35. Chen W, Wu W, Cheng J, Zhang Y, Chen Y et al. (2014) Detection of the deletion on Yp11.2 in a Chinese population. Forensic Sci Int Genet 8: 73-79.

36. Lattanzi W, Di Giacomo MC, Lenato GM, Chimienti G, Voglino G et al. (2005) A large interstitial deletion encompassing the amelogenin gene on the short arm of the $Y$ chromosome. Hum Genet 116: 395-401.

37. Jobling MA, Lo ICC, Turner DJ, Bowden GR, Lee AC et al. (2007) Structura variation on the short arm of the human $Y$ chromosome: Recurrent multigene deletions encompassing Amelogenin Y. Hum Mol Genet 16: 307-316.

38. Kumagai R, Sasaki Y, Tokuta T, Biwasaka H, Aoki Y (2008) DNA analaysis of family members with deletions in Yp11.2 region containing amelogenin locus. Leg Med 10: 39-42.

39. Turrina S, Filippini G, Voglino G, De Leo D (2011) Two additional reports of deletion on the short arm of the $\mathrm{Y}$ chromosome. Forensic Sci Int Genet 5 242-246.

40. Maciejewska A, Pawłowski R (2009) A rare mutation in the primer binding region of the Amelogenin X homologue gene. Forensic Sci Int Genet 3: 265267.

41. Shadrach B, Commane M, Hren C, Warshawsky I (2004) A rare mutation in the primer binding region of the amelogenin gene can interfere with gender identification. J Mol Diag 6: 401-405.

42. Stapleton PM, Lai D, Millar CD, Wu E, Andres M et al. (2008) Discovery of three related females who type $X Y$ at the amelogenin locus. Forensic Sci Int Genet Supplement Series 1: 577-579.

43. Sinclair AH, Berta P, Palmer MS, Hawkins JR, Griffiths BL et al. (1990) A gene from the human sex-determining region encodes a protein with homology to a conserved DNA-binding motif. Nature 346: 240-244.

44. Shah VC, Smart V (1996) Human chromosome Y and SRY. Cell Biol Int 20 3-6.

45. Su H, Lau YFC (1993) Identification of the transcriptional unit, structural organization, and promoter sequence of the human sex-determining region $Y$ (SRY) gene, using a reverse genetic approach. Am J Hum Genet 52: 24-38.

46. Katoh K, Miyata T (1999) A heuristic approach of maximum likelihood method for inferring phylogenetic tree and an application to the mammalian SOX-3 origin of the testis-determining gene SRY. FEBS Lett 463: 129-132.

47. Gubbay J, Collignon J, Koopman P, Capel B, Economou A et al. (1990) A gene mapping to the sex-determining region of the mouse $Y$ chromosome is a member of a novel family of embryonically expressed genes. Nature 346 $245-250$

48. Tozzo P, Giuliodori A, Corato S, Ponzano E, Rodriguez D et al. (2013) Deletion of amelogenin Y-locus in forensics: Literature revision and description of a novel method for sex confirmation. J Forensic Leg Med 20: 387-391.

49. Drobnič K (2006) A new primer set in a SRY gene for sex identification. Int Cong Series 1288: 268-270.

50. Lo YM, Tein MS, Lau TK, Haines CJ, Leung TN et al. (1998) Quantitative analysis of fetal DNA in maternal plasma and serum: implication for noninvasive prenatal diagnosis. Am J Hum Genet 63:768-775.

51. Kastelic V, Budowle B, Drobnič K (2009) Validation of SRY Marker for Forensic Casework Analysis. J Forensic Sci 54: 551-555. 
52. Luptáková L, Bábelová A, Omelka R, Kolena B, Vondráková M et al. (2011) Sex determination of early medieval individuals through nested PCR using a new primer set in the SRY gene. Forensic Sci Int 207: 1-5.

53. Giacalone J, Friedes J, Francke U (1992) A novel GC-rich human macrosatellite VNTR in Xq24 is differentially methylated on active and inactive X chromosomes. Nat Genet 1: 137-143.

54. Tremblay DC, Moseley S, Chadwick BP (2011) Variation in array size, monomer composition and expression of the macrosatellite DXZ4. PLoS One 6: e18969

55. Morikawa T, Yamamoto Y, Miyaish S (2011) A new method for sex determination based on detection of SRY, STS and amelogenin gene regions with simultaneous amplification of their homologous sequences by a multiplex PCR. Acta Med Okayama 65: 113-122.

56. Zhang JS, Yang-Feng TL, Muller U, Mohandas TK, De Jong PJ et al. (1992) Molecular isolation and characterization of an expressed gene from the human Y chromosome. Hum Mol Genet 1: 717-726.

57. Schnieders F, Dörk T, Arnemann J, Vogel T, Werner M et al. (1996) Testisspecific protein, Y-encoded (TSPY) expression in testicular tissues. Hum Mol Genet 5: 1801-1807.

58. Giachini C, Nuti F, Turner DJ, Laface I, Xue Y et al. (2009) TSPY1 copy number variation influences spermatogenesis and shows differences among Y lineages. J Clin Endocrinol Metab 94: 4016-4022.

59. Vodicka R, Vrtel R, Dusek L, Singh AR, Krizova K et al. (2007) TSPY gene copy number as a potential new risk factor for male infertility. Reprod BioMed Online 14: 597-587.

60. Shen Y, Yan Y, Lui Y, Zhang S, Yang D et al. (2013) A significant effect of the TSPY1 copy number on spermatogenesis efficiency and the phenotypic expression of the gr/gr deletion. Hum Mol Genet 22: 1679-1695.

61. Svacinova V, Vodicka R, Vrtel R, Godava M, Kvapilova M et al. (2011) Sequence recombination in exon 1 of the TSPY gene in men with impaired fertility. Biomed Pap Med Fac Univ Palacky Olomouc Czech Repub 155: 287 298

62. Manz E, Schnieders F, Brechlin AM, Schmidtke J (1993) TSPY-related sequences represent a microheterogeneous gene family organized as constitutive elements in DYZ5 tandem repeat units on the human $Y$ chromosome. Genomics 17: 726-731.

63. Ratti A, Stuppia L, Gatta V, Fogh I, Calabrese G et al. (2000) Characterization of a new TSPY gene family member in Yq (TSPYq1). Cytogenet Cell Genet 88: 159-162.

64. Dechend F, Williams G, Skawran B, Schubert S, Krawczak M et al. (2000) TSPY variants in six loci on the human Y chromosome. Cytogenet Cell Genet 91: 67-71.

65. Arnemann J, Jakubiczka S, Thüring S, Schmidtke J (1991) Cloning and sequence analysis of a human $\mathrm{Y}$-chromosome-derived, testicular cDNA TSPY. Genomics 11: 108-114.

66. Tyler-Smith C, Taylor L, Muller U (1988) Structure of a hypervariable tandemly repeated DNA sequence on the short arm of the human $Y$ chromosome. $J$ Mol Biol 203: 837-848.

67. Skaletsky H, Kuroda-Kawaguchl T, Minx PJ, Cordum HS, HIllier L et al (2003) The male-specific region of the human $Y$ chromosome is a mosaic of discrete sequence classes. Nature 423: 825-837.

68. Nickkholgh B, Noordam MJ, Hovingh SE, Van Pelt AMM, Van Der Veen F et al. (2010) Y chromosome TSPY copy numbers and semen quality. Fertil Steril 94: $1744-1747$

69. Hromadnikova I, Benesova M, Zejskova L, Stehnova J, Doucha J et al. (2009) The effect of DYS-14 copy number variations on extracellular fetal DNA quantification in maternal circulation. DNA Cell Biol 28: 351-358.

70. Delbridge ML, Longepied G, Depetris D, Mattei MG, Disteche CM, et al. (2004)
TSPY, the candidate gonadoblastoma gene on the human $Y$ chromosome, has a widely expressed homologue on the $\mathrm{X}$ - implications for $\mathrm{Y}$ chromosome evolution. Chromosome Res 12: 345-356.

71. Kamodyová N, Durdiaková J, Celec P, Sedláčková T, Repiská G et al. (2013) Prevalence and persistence of male DNA identified in mixed saliva samples after intense kissing. Forensic Sci Int Genet 7: 124-128.

72. Zimmermann B, El-Sheikhah A, Nicolaides K, Holzgreve W, Hahn S (2005) Optimized real-time quantitative PCR measurement of male fetal DNA in maternal plasma. Clin Chem 51: 1598-1604

73. Blagodatskikh EG, Nikitin AG, Seregin YA, Blagodatskikh KA, Nosikov VV (2010) Sex determination in biological specimens using the DYS14 marker. Mol Biol 44: 568-570.

74. Jacot TA, Zalenskaya I, Mauck C, Archer DF, Doncel GF (2013) TSPY4 is a novel sperm-specific biomarker of semen exposure in human cervicovaginal fluids; Potential use in HIV prevention and contraception studies. Contraception 88: 387-395

75. Campos E, Pitta D, Costa F, Campos V, Yela, D et al. (2014) DNA extraction from filter-paper spots of vaginal samples collected after sexual violence. Int J Gynecol Obstet 126: 23-27.

76. Nicklas J, Buel E (2006) Simultaneous determination of total human and male DNA using a duplex real-time PCR assay. J Forensic Sci 51:1005-1015.

77. Benoit JN, Quatrehomme G, Carle GF, Pognonec P (2013) An alternative procedure for extraction of DNA from ancient and weathered bone fragments. Med Sci Law 53: 100-106.

78. Mukerjee S, Mukherjee M, Ghosh T, Kalpana D, Sharma AK (2013) Differentia pattern of genetic variability at the DXYS156 locus on homologous regions of $X$ and $y$ chromosomes in Indian population and its forensic implications. Int $J$ Legal Med 127: 1-6.

79. Chen H, Lowther W, Avramopoulos D, Antonarakis SE (1994) Homologous loci DXYS156X and DXYS156Y contain a polymorphic pentanucleotide repeat (TAAAA) $n$ and map to human $X$ and $Y$ chromosomes. Hum Mutat 4: 208-211.

80. Calì F, Forster P, Kersting C, Mirisola MG, D'Anna R et al. (2002) DXYS156: A multi-purpose short tandem repeat locus for determination of sex, paternal and maternal geographic origins and DNA fingerprinting. Int J Legal Med 116: 133-138.

81. Torres-Rodríguez M, Martínez-Cortes G, Páez-Riberos LA, Sandoval L, Muñoz-Valle JF et al. (2006) Forensic potential of the STR DXYS156 in Mexican populations: Inference of X-linked allele null. Leg Med 8: 52-54.

82. Kersting C, Hohoff C, Rolf B, Brinkmann B (2001) Pentanucleotide short tandem repeat locus DXYS156 displays different patterns of variations in human populations. Croat Med J 42: 310-314.

83. Reed MJ, Purohit A, Woo L, Newman SP, Potter, BV (2005) Steroid sulfatase: molecular biology, regulation, and inhibition. Endocr Rev 26: 171-202.

84. Shapiro L, Yen P, Pomerantz D, Martin E, Rolewic L et al. (1989) Molecula studies of deletions at the human steroid sulfatase locus. Proc Natl Acad Sci U S A 86: 8477-8481.

85. Alperin ES, Shapiro LJ (1997) Characterization of point mutations in patients with X-linked ichthyosis: Effects on the structure and function of the steroid sulfatase protein. J Biol Chem 272: 20756-20763.

86. Furrow A, Theisen A, Velsher L, Bawle EV, Sastry S et al. (2011) Duplication of the STS region in males is a benign copy-number variant. Am J Med Genet A 155: 1972-1975.

87. Yen PH, Marsh B, Allen E, Tsai SP, Ellison J et al. (1988) The human X-linked steroid sulfatase gene and a Y-encoded pseudogene: Evidence for an inversion of the $Y$ chromosome during primate evolution. Cell 55: 1123-1135.

88. Hares DR (2012) Expanding the CODIS core loci in the United States. Forensic Sci Int Genet 6: e52-54. 